\title{
BMJ Open Sociodemographic and health-related determinants for making repeated calls to a medical helpline: a prospective cohort study
}

\author{
Mitti Blakoe, ${ }^{\oplus 1,2}$ Hejdi Gamst-Jensen, ${ }^{1}$ My von Euler-Chelpin, ${ }^{3}$ \\ Helle Collatz Christensen, ${ }^{1}$ Tom Møller ${ }^{2,4}$
}

To cite: Blakoe M, GamstJensen $\mathrm{H}$, von Euler-Chelpin M, et al. Sociodemographic and health-related determinants for making repeated calls to a medical helpline: a prospective cohort study. BMJ Open 2019;9:e030173. doi:10.1136/ bmjopen-2019-030173

- Prepublication history for this paper is available online. To view these files, please visit the journal online (http://dx.doi. org/10.1136/bmjopen-2019030173).

Received 4 March 2019 Revised 19 June 2019 Accepted 21 June 2019

Check for updates

(c) Author(s) (or their employer(s)) 2019. Re-use permitted under CC BY-NC. No commercial re-use. See rights and permissions. Published by BMJ.

${ }^{1}$ Emergency Medical Services Copenhagen, Emergency Medical Services Copenhagen, Ballerup, Denmark

${ }^{2}$ University of Copenhagen Faculty of Health Sciences, Copenhagen, Denmark ${ }^{3}$ Department of Public Health, University of Copenhagen Faculty of Health Sciences, Copenhagen, Denmark

${ }^{4}$ The University Hospitals Centre for Health Research, Copenhagen, Denmark

Correspondence to

Ms Mitti Blakoe;

mitti.blakoe@regionh.dk

\section{ABSTRACT}

Objectives To identify sociodemographic and healthrelated characteristics of callers' making repeated calls within 48 hours to a medical helpline, compared with those who only call once.

Setting In the Capital Region of Denmark people with acute, non-life-threatening illnesses or injuries are triaged through a single-tier medical helpline for acute, healthcare services.

Participants People who called the medical helpline between 18 January and 9 February 2017 were invited to participate in the survey. During the period, 38787 calls were handled and 12902 agreed to participate. Calls were excluded because of the temporary civil registration number $(\mathrm{n}=78)$, the call was not made by the patient or a close relative $(n=699)$, or survey responses were incomplete $(n=19)$. Hence, the analysis included 12106 calls, representing 11.131 callers' making single calls and 464 callers' making two or more calls within 48 hours. Callers' data (age, sex and caller identification) were collected from the medical helpline's electronic records. Data were enriched using the callers' self-rated health, self-evaluated degree of worry, and registry data on income, ethnicity and comorbidities. The OR for making repeated calls was calculated in a crude, sex-adjusted and age-adjusted analysis and in a mutually adjusted analysis. Results The crude logistic regression analysis showed that age, self-rated health, self-evaluated degree of worry, income, ethnicity and comorbidities were significantly associated with making repeated calls. In the mutually adjusted analysis associations decreased, however, odds ratios remained significantly decreased for callers with a household income in the middle $(\mathrm{OR}=0.71 ; 95 \% \mathrm{Cl} 0.54$ to 0.92 ) or highest ( $\mathrm{OR}=0.68 ; 95 \% \mathrm{Cl} 0.48$ to 0.96$)$ quartiles, whereas immigrants had borderline significantly increased $\mathrm{OR}(\mathrm{OR}=1.34 ; 95 \% \mathrm{Cl} 0.96$ to 1.86$)$ for making repeated calls.

Conclusions Findings suggest that income and ethnicity are potential determinants of callers' need to make additional calls within 48 hours to a medical helpline with triage function.

\section{INTRODUCTION}

In the last decade, out-of-hours $(\mathrm{OOH})$ primary care has taken place in large-scale organisations
Strengths and limitations of this study

- The characteristics of callers' who make repeated calls to a medical helpline with triage function have not previously been studied.

- This study provided an overview of the frequency of sociodemographic and health-related characteristics and its association with callers' who repeatedly call a medical helpline, compared with those who only call once.

- The sociodemographic and health-related characteristics influence the odds for making repeated calls to a medical helpline was calculated in sex-adjusted and age-adjusted analysis and in a mutually adjusted logistic regression analysis.

- The sociodemographic characteristics influence on making repeated calls compared with the health-related characteristics is illustrated.

- In the present study, $33.3 \%$ of the invited study population agreed to participate in the survey, possibly introducing selection bias.

in various countries, ${ }^{1}$ and telephone triage is a common feature of $\mathrm{OOH}$ services, serving to determine the level of urgency and healthcare needed. ${ }^{2}$ In the Capital Region of Denmark, people with acute, non-life-threatening illnesses or injuries are encouraged to call a single-tier telephone preadmission evaluation and triage service called medical helpline 1813 (MH1813). ${ }^{3}$ Triage results in one of two possible outcomes: (1): face-to-face consultation (home visit, hospital-based emergency department/acute care clinic or hospitalisation) or (2) medical telephone advice (self-care, contact general practitioner or prescriptions). ${ }^{4}$ Telephone triage, however, is not straight forward, and a lack of visual cues compromises clinical decision making. ${ }^{4}$ The call handler creates a picture of the caller using non-verbal cues, such as tone of voice, diction and background noises to help determine the urgency of the call. ${ }^{5}$ When using this strategy, call handlers subconsciously 
incorporate their own preconceptions and stereotypes, ${ }^{6}$ not to mention professional and personal experience. ${ }^{6}$ An additional complicating factor in the clinical decision making is that the call handler must simultaneously act as a gatekeeper and as a caregiver. ${ }^{7}$

Furthermore, when telephone medical helplines serve as a single-tier entry point for face-to-face consultations, callers must have the ability to describe symptoms sufficiently and follow the given medical advice adequately; ${ }^{28}$ however, the callers' ability to do so may vary. ${ }^{9}$ A lack of ability may increase the risk of receiving inaccurate advice or incorrect triage outcome, ${ }^{10}$ potentially increasing the need to make additional calls.

There is a lack of studies on whether sociodemographic and health-related characteristics are related to repeated calls to medical helplines. Existing literature on users of $\mathrm{OOH}$ services with face-to-face consultations (eg, emergency departments) has shown that sociodemographic and health-related characteristics are associated with repeat visits ${ }^{11-14}$ and that specific characteristics can add to the risk of making errors in clinical decision making. ${ }^{11}{ }^{15-18}$ Frequent use of $\mathrm{OOH}$ services is associated with the presence of comorbidities, ${ }^{819}$ whereas low, selfrated health $(\mathrm{SRH})$ is associated with frequent general practice visits in Denmark. ${ }^{20}$ Similarly, immigrants use the emergency room more often than ethnic Danes. ${ }^{21}$

Identification of the sociodemographic and health-related determinants for making repeated calls to medical helplines may help prevent errors in clinical decision making, preventing overtriage or undertriage in medical helplines. In addition, by gaining insight into underlying determinants to perform repeated calls, policy-makers might be provided with knowledge that potentially helps prevent the portion of repeated calls that may be unnecessary and resource demanding.

The aim of this paper was to identify the sociodemographic and health-related characteristics of individuals making repeated calls to a medical helpline within 48 hours, compared with those who only call once.

\section{METHODS}

\section{Design}

A prospective cohort study was conducted of individuals who repeatedly called MH1813 within 48 hours of their initial call $(n=464)$ compared with those who only called once $(n=11131)$. The differences between the two groups were examined in relation to sociodemographic (income and ethnicity) and health-related characteristics (age, sex, degree of comorbidities, SRH and self-evaluated degree of worry (DOW)). We also analysed the influence of the details on the initial call (time of call and caller) to MH1813.

\section{Setting}

The study was conducted at Emergency Medical Services Copenhagen in the Capital Region of Denmark, which provides acute and emergency services for 1.7 million people. Access to public medical healthcare services is free of charge in Denmark. MH1813 is a round-the-clock, singletier entry point for acute healthcare for people with acute, non-life-threatening illnesses or injuries and encourages people to call for preassessment and possible triage to a faceto-face consultation outside the office hours of general practitioners. ${ }^{3}$ A separate three-digit emergency number, 112, is available for potentially life-threatening symptoms/injuries and to request an ambulance.

The MH1813 medical staff handle approximately 1 million calls annually, $4 \%$ of which are repeat calls within 48 hours of the initial call. ${ }^{22}$ Call handlers at MH1813 comprise nurses $(80 \%)$ and physicians $(20 \%)$, who use an electronic decision support tool to determine the level of urgency and healthcare needed. ${ }^{3}$

The present study is embedded within a wider trial examining DOW as a predictor for the use of acute healthcare services and is registered at www.clinicaltrials. gov, file no. NCT02979457.

\section{Approvals and registration}

This study was approved by the Danish Data Protection Agency (2012-58-0004) and Statistics Denmark. Approval from the Scientific Ethics Review Committee of the Capital Region of Denmark was requested but no permission is required (H-15016323). Informed oral consent was obtained from all study participants.

\section{Participants}

Anyone who called MH1813 between 18 January and 9 February 2017 was invited to participate in a survey. If the caller agreed to participate, the survey was completed prior to speaking with the call handler. During this period, 38787 people called, 12902 of whom agreed to participate in the study $(33.26 \%)$. Callers were excluded if they had a temporary civil registration number (eg, tourists) $(\mathrm{n}=78)$; the call was not made by the patient or a close relative to the patient (eg, primary care nurses) $(n=699)$; or survey responses were incomplete $(n=19)$, leaving 12106 calls for analysis, as shown in figure 1 .

Initially we divided the calls included in the study cohort into the following four sequences: (1) one-time callers, where the individual only called once within 48 hours ( $\mathrm{n}=11131)$; (2) initial call plus the occurrence of repeated call $(n=464)$; (3) first repeated call within 48 hours of the initial call $(n=464)$; and (4) two or more repeated calls within 48 hours of the initial call $(n=47)$. Figure 2 illustrates the four sequences. For the analysis,

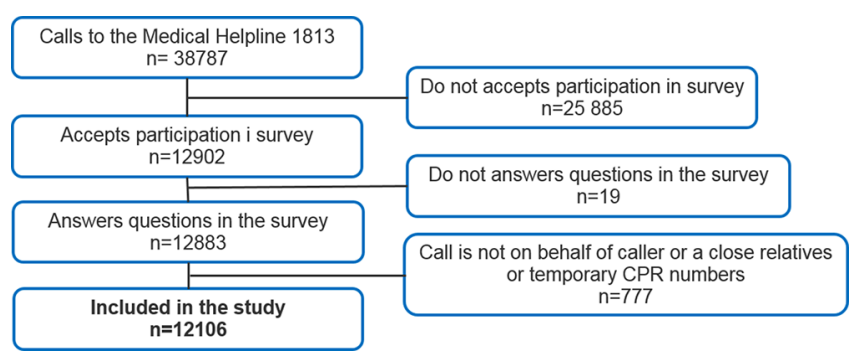

Figure 1 Flowchart of calls included. 


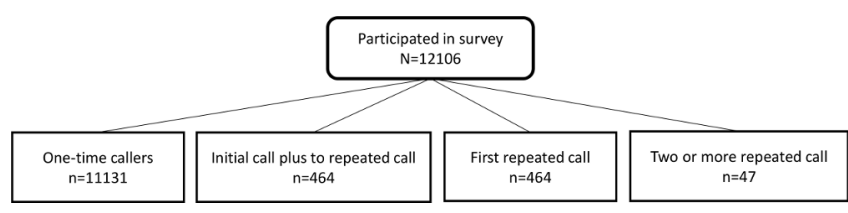

Figure 2 Division of the included calls into four strata: onetime callers, initial calls plus occurrence of repeated call, first repeated call within 48 hours and two or more repeated calls within 48 hours of the initial call.

however, we divided the study data into two main groups: one-time calls $(n=11131)$ and the initial call to the repeated calls $(n=464)$.

\section{Exposure}

Data on sex (male, female) and age ( $\leq 5,6-18$, 19-65 and >65 years) were retrieved from MH1813's electronic patient record. This classification of age was selected based on disease patterns in the respective age groups (children, adolescents, adults and the elderly). Time of call (workday and weekend) was retrieved from the same electronic patient record.

Prior to speaking with the call handler, caller responses to three survey questions were collected: self-evaluated DOW (1=low, $2=$ middle, $3=$ high) and SRH (on a scale of 1 to 5 , where $1=$ very good and $5=$ very poor) and who the caller was (patient, close relative to the patient and other). A recorded message presented the survey questions, which callers responded to on a numeric scale using their phone keypad.

DOW represents a self-evaluated measure of the caller's level of worry concerning the acuteness of their health situation. Although this scale has not been validated a previous study showed that people using $\mathrm{OOH}$ services were able to rate their DOW as a measure of the self-evaluated level of urgency at MH1813. ${ }^{23} 24$

SRH reflects an individual's own assessment of their health according to their own definition of health. SRH is a validated scale that predicts morbidity and mortality, ${ }^{25}$ and also prompts people to seek primary care more frequently. ${ }^{20} 26$

All residents of Denmark are assigned a personal identification number at birth or on officially registering in the Danish Civil Registration System. ${ }^{27} 28$ This number makes it possible to conduct individual follow-up in national registries. Call data on each caller were merged with data on annual household income divided into four quartiles (very low, low, middle and high) and ethnicity (natives, immigrants and descendants of immigrants) from Statistics Denmark's registries. ${ }^{29}$ Data on comorbidity from the past 10 years (Charlson score: $0=$ no comorbidities, $1=$ one comorbidity, $2=$ two or more comorbidities) were obtained from the Danish National Patient Registry, ${ }^{30} 31$ where morbidity is registered continuously for all patients in Danish hospitals. The validity of the Danish National Patient Registry is estimated at 66\%-99\% compared with a journal audit. $^{32}$

\section{Analysis}

A descriptive baseline analysis of sociodemographic and health-related characteristics was performed using frequency distributions (number and percentage). Logistic regression analyses were used to calculate crude, age -adjusted and sex-adjusted and mutually adjusted (for age, sex, ethnicity, income, call time, caller, DOW, SRH and Charlson comorbidity score) ORs with $95 \%$ CIs for repeat callers $(n=464)$ versus one-time callers $(n=11131)$.

Due to the limited number of missing values in the data collection ( $\mathrm{n}=106$ in SRH), they were excluded from the analysis because their absence was considered random.

The statistical analyses were performed using SAS Enterprise Guide 7.1.

\section{RESULTS}

The analysis included 11595 callers, 4\% ( $\mathrm{n}=464)$ of whom represented callers who made repeated calls within 48 hours of their initial call.

The results of the crude analysis identified an association between repeated calls to MH1813 within 48 hours and the callers' sociodemographic and health-related characteristics, as well as the details related to the call. However, these associations decreased in the mutually adjusted analysis, indicating that sociodemographic and health-related characteristics have a reinforcing effect on the need to make an additional call.

A comparison of the results in the mutually adjusted analysis showed that sociodemographic variables have a stronger association with the odds of making a repeat call within 48 hours compared with the health-related variables (figure 3 ).

Findings in the mutually adjusted analysis suggest that income and ethnicity are potential determinants for individuals need to make repeated calls within 48 hours to a medical helpline with triage function.

\section{Association of health-related characteristics with making repeated calls}

The crude analysis on the health-related characteristics (age, sex, DOW, SRH and Charlson comorbidity score) indicated that all characteristics, except sex, were significantly associated with the odds of making repeated calls. The strongest positive association for making a repeat call was a Charlson comorbidity score of 2 compared with a score of $0(\mathrm{OR}=1.66 ; 95 \%$ CI 1.26 to 2.19$)$ (table 1$)$.

In the mutually adjusted logistic regression analysis, the ORs decreased somewhat, and none of the health-related characteristics were significantly associated with the odds of performing a repeated call (table 1$)$.

\section{Association of sociodemographic characteristics with making repeated calls}

The crude analysis on the sociodemographic characteristics (household income and ethnicity) indicated that immigrant status increased the odds of performing a repeated call, whereas having a middle or a high 


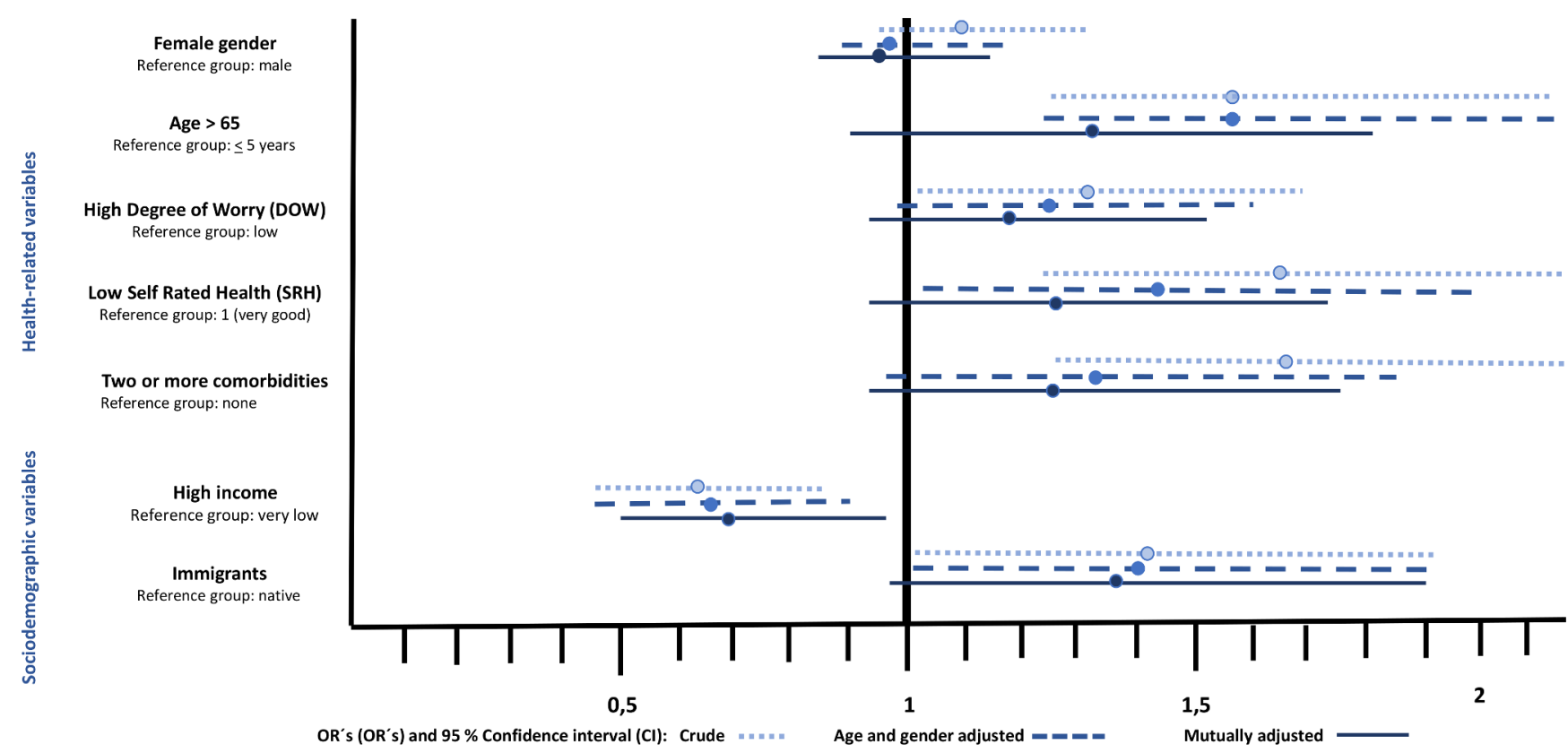

Figure 3 Showing Crude, age-adjusted and gender-adjusted, and mutually adjusted ORs with $95 \% \mathrm{Cl}$ for health-related and sociodemographic characteristics for repeated calls <48hours $(n=464)$ compared with single calls $(n=11131)$ to the medical helpline.

household income decreased the odds of performing a repeated call (table 2 ).

In the mutually adjusted logistic regression analysis, annual income significantly decreased the odds of performing a repeated call for callers' with household income in the middle quartile $(\mathrm{OR}=0.71 ; 95 \%$ CI 0.54 to 0.92 ) and highest quartiles ( $\mathrm{OR}=0.68 ; 95 \%$ CI 0.48 to $0.96)$, compared with callers' with household income in the lowest quartile (table 2). This result indicates that low income is a potential determinant for performing repeated calls to the $\mathrm{MH} 1813$.

Immigrants relative to natives had significantly increased odds for performing repeated calls, in the crude analysis, as well as the analyses adjusted for age and sex. In the mutually adjusted analysis, the association was borderline significant ( $\mathrm{OR}=1.34 ; 95 \%$ CI 0.96 to 1.85 ). This result indicates that being an immigrant also is a potential determinant for performing repeated calls to the MH1813 (table 2).

\section{Characteristics associated with calls to MH1813 and with making repeat calls}

The crude analysis on characteristics related to the call found that callers' who were a close relative to the patient were significantly associated with performing a repeated call, whereas the time of call did not have an association with performing a repeated call (table 3 ).

In the mutually adjusted logistic regression analysis, callers who were close relatives had significantly decreased odds for making repeated calls compared with callers who were patients $(\mathrm{OR}=0.75 ; 95 \%$ CI 0.59 to 0.94$)$ (table 3$)$.

\section{DISCUSSION}

The main finding is that the association between callers' sociodemographic characteristics (income and ethnicity) and repeated calls to the MH1813 within 48 hours is stronger than for the callers' health-related characteristics (age, sex, comorbidity, SRH and DOW) (figure 3). Sociodemographic factors have also been shown to be an influence among people with repeated visits to $\mathrm{OOH}$ services with face-to-face consultations. ${ }^{20} 212633-35$ This indicates that the MH1813 reflects similar patterns among people with low income and people who are immigrants, as seen in the $\mathrm{OOH}$ services in general.

Specific clinical factors, such as the call handlers' level of professional experience or language barriers, may also have affected the individual's need to call more than once. Identification of these factors is beyond the scope of this survey but is a relevant issue to explore in future studies.

The mutually adjusted analysis showed that household income was the only investigated variable that was significantly associated with making repeated calls. Our results indicate that high household income may represent a factor that leads to the occurrence of fewer repeated call within 48 hours of the initial call, whereas low household income may be a determinant for making repeated calls. This finding is supported by evidence showing that low socioeconomic status is related to the extent of comorbidity, ${ }^{36}$ which may increase the need for a professional assessment of the severity of symptoms. Moreover, low socioeconomic status is related to increased use of medical services in general. ${ }^{35} 37$ 
Table 1 Crude, adjusted and full model adjusted ORs with 95\% Cls for health-related characteristics for repeated calls $<48$ hours $(\mathrm{N}=464)$ compared with one-time calls $(\mathrm{N}=11131)$ to the telephone triage

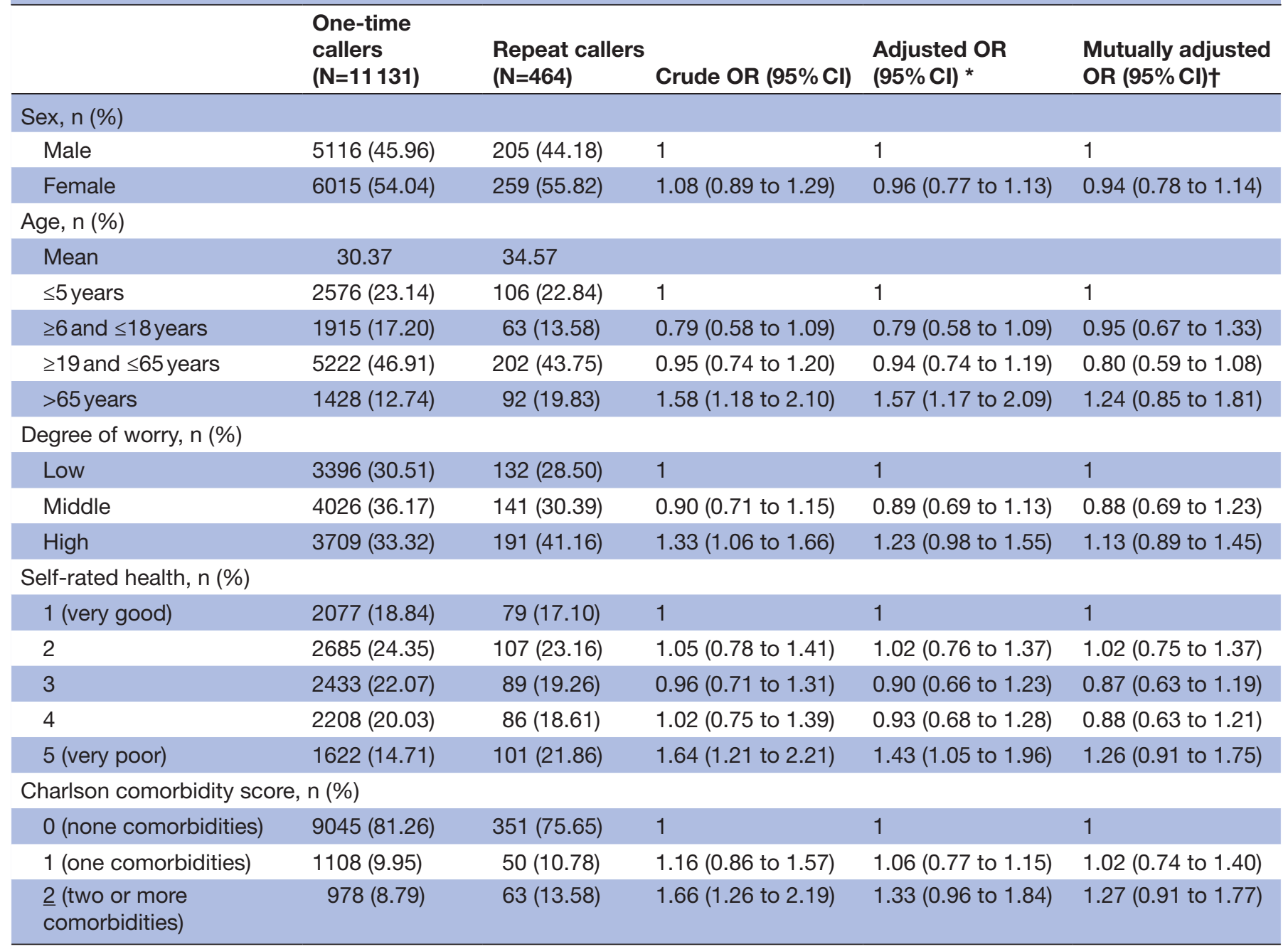

${ }^{*}$ Adjusted for age and sex.

†Adjusted for age, sex, ethnicity, income, call time, caller, degree of worry, self-rated health and Charlson comorbidity score.

In relation to ethnicity, the frequency distribution showed that $7.2 \%$ of one-time callers were immigrants, which should be seen in the light of the fact that immigrants make up $10.31 \%$ of the general population in Denmark. ${ }^{38}$ Determining whether fewer immigrants use MH1813, or whether fewer immigrants declined to participate in the survey, is not possible based on the present data. The existing literature, however, indicates that immigrants generally use $\mathrm{OOH}$ acute healthcare with face-toface consultations more frequently than ethnic Danes. ${ }^{21}$

The mutually adjusted analysis showed that immigrants had insignificantly higher odds of making repeated calls compared with ethnic Danes. One possible reason for this is that immigrants with limited language skills may lack the vocabulary to adequately describe their symptoms on the telephone. ${ }^{39} 40$ According to Hansen and Hunskaar, who studied adherence to the advice given by a nurse on the telephone, callers' who were immigrants had a significantly lower level of trust in the nurses and felt that they did not receive relevant answers to questions compared with natives. ${ }^{41}$

In the frequency distribution between repeated callers' and one-time callers, sex was not associated with repeated calls. Nevertheless, there were a higher amount of women among one-time callers $(54.04 \%)$ and repeat callers $(55.82 \%)$ compared with the distribution of women in the general Danish population $(50.25 \%){ }^{38}$ This distribution is similar to previous studies on $\mathrm{OOH}$ services. ${ }^{2} 4243$ Women generally contact medical helplines more often than men and usually report a lower SRH than men $^{44}$ and a higher DOW. ${ }^{23}$

The distribution of comorbidity in the study population showed that people with the highest strata of comorbidity made repeated calls more frequently $(13.58 \%)$ than one-time calls $(8.79 \%)$. This is in line with the existing literature, where people with chronic diseases have a higher rate of repeated inquiries to emergency departments than those without chronic diseases. ${ }^{45-47}$ One 
Table 2 Crude, adjusted and full model adjusted ORs with 95\% Cls for sociodemographic characteristics for repeated calls $<48$ hours $(\mathrm{N}=464)$ compared with one-time calls $(\mathrm{N}=11131)$ to the telephone triage

\begin{tabular}{|c|c|c|c|c|c|}
\hline & $\begin{array}{l}\text { One-time callers } \\
(\mathrm{N}=11131)\end{array}$ & $\begin{array}{l}\text { Repeat callers } \\
(\mathrm{N}=464)\end{array}$ & Crude OR $(95 \% \mathrm{Cl})$ & $\begin{array}{l}\text { Adjusted OR } \\
(95 \% \mathrm{Cl})^{*}\end{array}$ & $\begin{array}{l}\text { Mutually adjusted } \\
\text { OR }(95 \% \mathrm{Cl}) \dagger\end{array}$ \\
\hline \multicolumn{6}{|l|}{ Ethnicity, n (\%) } \\
\hline Immigrants & $833(7.22)$ & $47(10.17)$ & 1.41 (1.03 to 1.93$)$ & 1.40 (1.02 to 1.93$)$ & $1.34(0.96$ to 1.86$)$ \\
\hline $\begin{array}{l}\text { Descendants of } \\
\text { immigrants }\end{array}$ & $754(6.54)$ & $35(7.57)$ & $1.16(0.81$ to 1.65$)$ & 1.27 (0.89 to 1.82$)$ & $1.14(0.79$ to 1.65$)$ \\
\hline Very low & $3151(28.31)$ & 156 (33.62) & 1 & 1 & 1 \\
\hline Low & $3139(28.20)$ & 147 (31.68) & 0.95 (0.75 to 1.19$)$ & $0.82(0.64$ to 1.06$)$ & 0.81 (0.63 to 1.05$)$ \\
\hline Middle & 3198 (28.73) & $110(23.71)$ & $0.69(0.54$ to 0.89$)$ & 1.03 (0.80 to 1.33$)$ & 0.71 (0.54 to 0.92$)$ \\
\hline High & $1643(14.76)$ & $51(10.99)$ & $0.63(0.46$ to 0.87$)$ & 0.65 (0.46 to 0.91$)$ & 0.68 (0.48 to 0.96$)$ \\
\hline
\end{tabular}

${ }^{*}$ Adjusted for age and sex.

†Adjusted for age, sex, ethnicity, income, call time, caller, degree of worry, self-rated health and Charlson comorbidity score.

possible explanation is that people with multiple comorbidities have more progressive symptoms, increasing the need for repeated inquiries. ${ }^{8}$

The self-reported assessment of DOW and SRH was obtained in real time in conjunction with the call to MH1813, diminishing the risk of recall bias. SRH and DOW are simple, self-reported single-item variables that measure subjective, qualitative data using a quantitative method. ${ }^{48}$ Poor self-evaluated health is a factor that prompts people to seek primary care more frequently. ${ }^{2026}$ In the present study, the crude analysis showed that very poor SRH (score $=5$ ) was significantly associated with the need to make repeated calls compared with very good SRH (score=1). Likewise, the crude analysis indicated that high DOW was significantly associated with the need to make repeated calls compared with low DOW. The observed association remained significant in the age and sex-adjusted analysis, indicating that SRH and DOW are potential predictors for repeated calls.

When a close relative made the call on behalf of the patient, the risk of a repeated call occurring was significantly reduced. We hypothesise that this result is due to the number of relatives who are parents of small children and request advice and guidance on how to handle a child's symptoms, reducing the need to call MH1813 again. The two youngest age groups $(0-5$ and 6-18 years) represented almost $40 \%$ of all the calls in this study, which means they are over-represented compared with the general population $(22.6 \%) .{ }^{38}$ This is in line with similar studies showing that younger people generally have a higher consumption of acute healthcare services. ${ }^{2} 154243$

Overall, the analysis of sociodemographic and health-related characteristics showed that associations between groups decreased in the adjusted analysis. This suggests that the variables under study had a reinforcing effect and do not independently characterise people who have a need to make repeated calls, indicating that identifying the underlying factors for the need to make repeated calls constitutes a complex issue.

\section{Limitations}

In the present study, 33.3\% of the study cohort invited to participate agreed to do the survey. In a comparative

Table 3 Crude, adjusted and full model adjusted ORs with 95\% Cls for characteristics attach to the call for repeated calls $<48$ hours $(\mathrm{N}=464)$ compared with one-time calls $(\mathrm{N}=11131)$ to the telephone triage

\begin{tabular}{|c|c|c|c|c|c|}
\hline & $\begin{array}{l}\text { One-time callers } \\
(\mathrm{N}=11131)\end{array}$ & $\begin{array}{l}\text { Repeat callers } \\
(\mathrm{N}=464)\end{array}$ & Crude OR $(95 \% \mathrm{Cl})$ & Adjusted OR $(95 \% \mathrm{Cl})$ * & $\begin{array}{l}\text { Mutually adjusted } \\
\text { OR }(95 \% \mathrm{Cl}) \dagger\end{array}$ \\
\hline \multicolumn{6}{|l|}{ Call time, n (\%) } \\
\hline Workday & $6777(60.88)$ & $275(59.27)$ & 1 & 1 & 1 \\
\hline Weekend & $4354(39.12)$ & $189(40.73)$ & 1.07 (0.88 to 1.29$)$ & 1.05 (0.87 to 1.27$)$ & 1.09 (0.89 to 1.32$)$ \\
\hline \multicolumn{6}{|l|}{ Caller, n (\%) } \\
\hline Patient & $4481(40.26)$ & $210(45.26)$ & 1 & 1 & 1 \\
\hline Close relative & $6650(59.74)$ & 254 (54.74) & 0.82 (0.67 to 0.98$)$ & 0.79 (0.64 to 1.00$)$ & 0.75 (0.59 to 0.94$)$ \\
\hline
\end{tabular}

${ }^{*}$ Adjusted for age and sex.

†Adjusted for age, sex, ethnicity, income, call time, caller, degree of worry, self-rated health and Charlson comorbidity score. 
analysis the participants did not differ significantly from non-responders in relation to age, sex and triage outcome. Nevertheless, selection bias might have been introduced in relation to other sociodemographic or health-related characteristics.

Data on comorbidity were obtained from the Danish National Patient Registry, ${ }^{31}$ which is why people may have had one or more unrecognised morbidities that had not received an in-hospital diagnosis and subsequent registration in the Danish National Patient Registry. This factor could potentially have led to an information bias in relation to the calculation of comorbidity scores in the present study. However, as this potential information bias would have been present in both people who made one-time calls and people who made repeated calls, it was considered a non-differential misclassification.

In this study, SRH and DOW are measured with a simplified numeric scale. SRH is recognised as a valid predictor of morbidity and mortality. ${ }^{48}$ DOW, however, is a less studied variable, which is why the validity cannot be accounted for, as is recommended for self-reported measurements. ${ }^{49}$

Because one of the aims of this study was to be able to implement results in decision making in clinical practice, the sociodemographic and health-related characteristics variables were not tested for interaction. Nevertheless, the existing evidence on the sociodemographic and health-related characteristics of interest suggest multiple interactions between variables, for example, a poor SRH interacts with age and with comorbidities ${ }^{50}$; a higher DOW interacts with female callers ${ }^{23}$; and immigrant status interacts with a lower self-perceived health and a higher rate of comorbidities. ${ }^{51}$ Testing for interaction in the statistical analysis could potentially have provided valuable insight into possible confounders but was considered outside the scope of this study.

\section{Implications for clinicians and policy-makers}

This study indicates that specific sociodemographic characteristics of callers are potential determinants of the callers' need to make repeated calls to a medical helpline with triage function. This implies that the health service needs of callers with certain sociodemographic characteristics may differ compared with other sociodemographic groups when calling a telephone medical helpline.

Recognising the sociodemographic characteristics that play a role is an important aspect of preventing undertriage, which poses a risk of delaying examination and treatment. One way of dealing with this issue is to provide call handlers with additional information about callers' sociodemographic and self-evaluated characteristics in the existing electronic decision support tool to supplement identification and clinical decision making in telephone triage.

The aim and design of this study provide knowledge on callers' determinants for performing repeated calls. However, the study does not provide knowledge on potential determinants related to the call handler, nor the interaction between caller and call handler during the initial call, which is relevant to investigate in future studies.

The results of this study are generalisable and can serve to benefit other large-scale $\mathrm{OOH}$ telephone triage services.

\section{CONCLUSIONS}

In the present study, $4 \%$ of the calls MH1813 received were from repeat callers. The crude analysis identified sociodemographic and health-related characteristics associated with making repeated calls. The mutually adjusted analysis showed that callers with a mid to high household income had significantly decreased odds for making repeated calls compared with those with very low income. Also, immigrants had insignificantly higher odds for making repeated calls compared with ethnic Danes. Other variables under study had a reinforcing effect on the odds of making repeated calls, which means they did not independently characterise people with a need to make additional calls.

These findings suggest that income and ethnicity are potential determinants for making repeated calls, which indicates that $\mathrm{OOH}$ telephone triage might benefit from incorporating sociodemographic characteristics in clinical decision making tools to prevent overtriage or undertriage.

\section{Patient and public involvement}

The development of the research aim, design, recruitment, conduct, and outcome measures in this study were not based on patient involvement. Participants can request further information on this study.

Acknowledgements The authors acknowledge the support of Jens Morten Haugaard, and especially Medical Emergency Services Copenhagen, in acquiring the scientific data and overall guidance.

Contributors MB, HG-J, ME and TM: conceptualised the study. MB and HG-J: participated in data extraction. MB and MvE-C: participated in data analysis. MB and TM: produced the first draft of the manuscript. HG-J, MvE-C, HCC and TM: provided overall guidance and a final review of all manuscript drafts.

Funding The authors have not declared a specific grant for this research from any funding agency in the public, commercial or not-for-profit sectors.

Competing interests None declared.

Patient consent for publication Not required.

Ethics approval The study was approved by the Danish Data Protective Agency (2012-58-0004). Approval from the Scientific Ethics Review Committee of the Capital Region of Denmark was requested but no permission is required (H-15016323).

Provenance and peer review Not commissioned; externally peer reviewed.

Data sharing statement Data may be obtained from a third party and are not publicly available. All data relevant to the study are included in the article or uploaded as supplementary information.

Open access This is an open access article distributed in accordance with the Creative Commons Attribution Non Commercial (CC BY-NC 4.0) license, which permits others to distribute, remix, adapt, build upon this work non-commercially, and license their derivative works on different terms, provided the original work is 
properly cited, appropriate credit is given, any changes made indicated, and the use is non-commercial. See: http://creativecommons.org/licenses/by-nc/4.0/.

\section{REFERENCES}

1. Huibers L, Giesen P, Wensing M, et al. Out-of-hours care in western countries: assessment of different organizational models. BMC Health Serv Res 2009;9:105.

2. Huibers L, Moth G, Carlsen AH, et al. Telephone triage by GPs in outof-hours primary care in Denmark: a prospective observational study of efficiency and relevance. Br J Gen Pract 2016;66:e667-e673.

3. Wadmann SKJ. Evaluering af enstrenget og visiteret akutsystem i Region Hovedstaden. Sammenfatning. Det nationale institut for komuners og regioners analyse og forskning 2015.

4. Leprohon J, Patel VL. Decision-making strategies for telephone triage in emergency medical services. Med Decis Making 1995;15:240-53.

5. Purc-Stephenson RJ, Thrasher C. Nurses' experiences with telephone triage and advice: a meta-ethnography. J Adv Nurs 2010;66:482-94.

6. Greenberg ME. A comprehensive model of the process of telephone nursing. J Adv Nurs 2009;65:2621-9.

7. Holmström I, Dall'Alba G. 'Carer and gatekeeper' - conflicting demands in nurses' experiences of telephone advisory services. Scand J Caring Sci 2002;16:142-8.

8. Flarup L, Moth G, Christensen MB, et al. Chronic-disease patients and their use of out-of-hours primary health care: a cross-sectional study. BMC Fam Pract 2014;15:114.

9. Gamst-Jensen H, Lippert FK, Egerod I. Under-triage in telephone consultation is related to non-normative symptom description and interpersonal communication: a mixed methods study. Scand $J$ Trauma Resusc Emerg Med 2017;25:52.

10. Bunn F, Byrne G, Kendall S. The effects of telephone consultation and triage on healthcare use and patient satisfaction: a systematic review. Br J Gen Pract 2005;55:956-61.

11. Verelst S, Pierloot S, Desruelles D, et al. Short-term unscheduled return visits of adult patients to the emergency department. $J$ Emerg Med 2014;47:131-9.

12. Cheng SY, Wang HT, Lee CW, et al. The characteristics and prognostic predictors of unplanned hospital admission within 72 hours after ED discharge. Am J Emerg Med 2013;31:1490-4.

13. Sabbatini AK, Kocher KE, Basu A, et al. In-Hospital Outcomes and Costs Among Patients Hospitalized During a Return Visit to the Emergency Department. JAMA 2016;315:663-71.

14. Martin-Gill C, Reiser RC. Risk factors for 72-hour admission to the ED. Am J Emerg Med 2004;22:448-53.

15. Huibers LA, Moth G, Bondevik GT, et al. Diagnostic scope in outof-hours primary care services in eight European countries: an observational study. BMC Fam Pract 2011;12:30.

16. Byrne M, Murphy AW, Plunkett PK, et al. Frequent attenders to an emergency department: a study of primary health care use, medical profile, and psychosocial characteristics. Ann Emerg Med 2003;41:309-18.

17. Di Giuseppe G, Abbate R, Albano L, et al. Characteristics of patients returning to emergency departments in Naples, Italy. BMC Health Serv Res 2008;8:97

18. McCusker J, Healey E, Bellavance F, et al. Predictors of repeat emergency department visits by elders. Acad Emerg Med 1997;4:581-8.

19. Huber CA, Rosemann T, Zoller M, et al. Out-of-hours demand in primary care: frequency, mode of contact and reasons for encounter in Switzerland. J Eval Clin Pract 2011;17:174-9.

20. Vedsted P, Fink P, Sørensen HT, et al. Physical, mental and social factors associated with frequent attendance in Danish general practice. A population-based cross-sectional study. Soc Sci Med 2004;59:813-23.

21. Norredam M, Krasnik A, Moller Sorensen T, et al. Emergency room utilization in Copenhagen: a comparison of immigrant groups and Danish-born residents. Scand J Public Health 2004;32:53-9.

22. Helpline Tepratm. 9 Jan 2018. 2017

23. Gamst-Jensen $\mathrm{H}$, Huibers L, Pedersen K, et al. Self-rated worry in acute care telephone triage: a mixed-methods study. $\mathrm{Br} J$ Gen Pract 2018;68:e197-e203.
24. Gamst-Jensen H, Frishknecht Christensen E, Lippert F, et al. Impact of caller's degree-of-worry on triage response in out-of-hours telephone consultations: a randomized controlled trial. Scand J Trauma Resusc Emerg Med 2019;27:44.

25. Chandola $T$, Jenkinson $C$. Validating self-rated health in different ethnic groups. Ethn Health 2000;5:151-9.

26. Vedsted $\mathrm{P}$, Christensen MB. Frequent attenders in general practice care: a literature review with special reference to methodological considerations. Public Health 2005;119:118-37.

27. Pedersen CB. The Danish Civil Registration System. Scand J Public Health 2011;39(7 Suppl):22-5.

28. Schmidt M, Pedersen L, Sørensen HT. The Danish Civil Registration System as a tool in epidemiology. Eur J Epidemiol 2014;29:541-9.

29. Thygesen $L$. The register-based system of demographic and social statistics in Denmark. Stat J UN Econ Comm Eur 1995;12:49-55.

30. Schmidt M, Schmidt SA, Sandegaard JL, et al. The Danish National Patient Registry: a review of content, data quality, and research potential. Clin Epidemiol 2015;7:449-90.

31. Lynge E, Sandegaard JL, Rebolj M. The Danish National Patient Register. Scand J Public Health 2011;39(7 Suppl):30-3.

32. Tn N. Datavaliditet og dækningsgrad i Landspatientregisteret. Ugeskr Læger 2002;164:33-7.

33. Maheswaran R, Pearson T, Jiwa M. Repeat attenders at National Health Service walk-in centres - a descriptive study using routine data. Public Health 2009;123:506-10.

34. Sandvik H, Hunskaar S. Frequent attenders at primary care out-ofhours services: a registry-based observational study in Norway. BMC Health Serv Res 2018;18:492.

35. Vedsted $P$, Olesen F. Social environment and frequent attendance in Danish general practice. Br J Gen Pract 2005;55:510-5.

36. Marmot M, Wilkinson RG. Social determinants of health: Oxford university press, 1999.

37. Marmot MW RG. Social determants of health: Oxford university press, 2003.

38. Statistik D. Statistikbanken. Available from: http:// wwwstatistikbankendk/statbank5a/defaultasp?w=1920 (cited 7 Apr 2018).

39. Wu Z, Penning MJ, Schimmele CM. Immigrant status and unmet health care needs. Can J Public Health 2005;96:369-73.

40. Njeru JW, Damodaran S, North F, et al. Telephone triage utilization among patients with limited English proficiency. BMC Health Serv Res 2017;17:706.

41. Hansen EH, Hunskaar S. Understanding of and adherence to advice after telephone counselling by nurse: a survey among callers to a primary emergency out-of-hours service in Norway. Scand J Trauma Resusc Emerg Med 2011;19:48.

42. Huibers L, Moth G, Andersen M, et al. Consumption in out-ofhours health care: Danes double Dutch? Scand J Prim Health Care 2014;32:44-50.

43. Moth G, Huibers L, Christensen MB, et al. Out-of-hours primary care: a population-based study of the diagnostic scope of telephone contacts. Fam Pract 2016;33:504-9.

44. Christensen ALE, Davidsen O, Juel, K M. Sundhed og sygelighed i Danmark 2010 \& udviklingen siden 1987 Statens Institut for Folkesundhed. Syddansk Universitet København 2012.

45. Flarup L, Carlsen AH, Moth G, et al. The 30-day prognosis of chronic-disease patients after contact with the out-of-hours service in primary healthcare. Scand J Prim Health Care 2014;32:208-16.

46. White D, Kaplan L, Eddy L. Characteristics of patients who return to the emergency department within 72 hours in one community hospital. Adv Emerg Nurs J 2011;33:344-53.

47. Sauvin G, Freund Y, Saïdi K, et al. Unscheduled return visits to the emergency department: consequences for triage. Acad Emerg Med 2013;20:33-9.

48. Idler EL, Benyamini Y. Self-rated health and mortality: a review of twenty-seven community studies. J Health Soc Behav 1997;38:21-37.

49. McKenna SP. Measuring patient-reported outcomes: moving beyond misplaced common sense to hard science. BMC Med 2011;9:86.

50. Jylhä M. What is self-rated health and why does it predict mortality? Towards a unified conceptual model. Soc Sci Med 2009;69:307-16.

51. Jervelund SS, Malik S, Ahlmark N, et al. Morbidity, self-perceived health and mortality among non-western immigrants and their descendants in denmark in a life phase perspective. J Immigr Minor Health 2017;19:448-76. 